\title{
SEQUÊNCIA DIDÁTICA COMO INSTRUMENTO DE PROMOÇÃO DA APRENDIZAGEM SIGNIFICATIVA
}

\author{
JAIR CURCINO MONTEIRO \\ Instituto Federal do Tocantins - IFTO \\ E-mail: jcurcino4@gmail.com \\ Weimar Silva CASTILHO \\ Instituto Federal do Tocantins - IFTO \\ E-mail:weimar@ifto.edu.br \\ WALLYSONN ALVES DE SOUZA \\ Instituto Federal do Tocantins - IFTO \\ E-mail:wallysonn.souza@ifto.edu.br
}

\section{RESUMO}

A utilização de diversas metodologias e modalidades didáticas mostra-se como uma estratégia válida e promissora na tentativa de atender as diferenças individuais dos alunos no que se refere à maneira como eles aprendem e se apropriam dos conteúdos abordados em sala de aula. O objetivo deste estudo é realizar uma revisão bibliográfica com base em estudos que visam promover uma aprendizagem significativa por meio da aplicação da sequência didática nas aulas de matemática.

\section{PalaVRas-ChaVe:}

Sequência Didática; Aprendizagem Significativa; Metodologias de Ensino.

\section{DIDACTIC SEQUENCE AS AN INSTRUMENT FOR PROMOTING SIGNIFICANT LEARNING}

\section{ABSTRACT}

The use of different didactics methodologies and modalities is shown to be a valid and promising strategy in an attempt to address the individual differences of students with regard to the way they learn and appropriate the contents covered in the classroom. The aim of this study is to carry out a literature review based on studies that aim to promote meaningful learning through the application of the didactic sequence in mathematics classes.

\section{KEYWORDS:}

Didactic Sequence; Meaningful Learning; Teaching Methodologies.

\section{INTRODUÇÃO}

A humanidade já acreditou que a aprendizagem se desenvolvia exclusivamente por meio da figura do professor que, na condição de dotado de saber, expunha um 
conteúdo novo aos alunos, e esses simplesmente aprendiam, em uma perspectiva mecânica, com profunda influência do meio sobre o sujeito, sem considerar sua capacidade reflexiva.

Atualmente nos meios de ensino compreende-se que as estratégias pedagógicas devem levar o aluno a pensar, questionar e criar suas próprias ideias e conceitos em sala de aula, dessa forma, os professores enfrentam desafios no processo de ensino e aprendizagem dos seus alunos, contudo buscam diferentes metodologias com a finalidade de melhorar a aprendizagem.

A utilização de diversas metodologias e modalidade didáticas mostra-se como uma estratégia válida e promissora na tentativa de atender as diferenças individuais dos alunos no que se refere à maneira como eles aprendem e se apropriam dos conteúdos abordados (TAXINI et al., 2012).

Roratto (2010) afirma que aprender Matemática não é uma tarefa fácil para grande parte dos estudantes, pois um dos fatores que contribuem para a dificuldade do aprendizado é o distanciamento entre a forma como é produzida e a forma como é ensinada essa ciência. Já Babinski (2017) ressalta que o ensino de matemática precisa estar interligado e contextualizado junto às outras áreas do conhecimento, de forma a criar um paralelo com as situações práticas do cotidiano.

Dessa forma a aprendizagem significativa promove a ideia de que o ensino necessita de um diálogo prévio entre professor e aluno, de modo a sondar o que estes compreendem a respeito de tal conceito, para que só então se possa acrescer novas ideias a esse, agregando conhecimento ao seu conhecimento prévio, com base em elementos conhecidos (AUSUBEL, 2003).

A sequência didática consiste em uma série de atividades que criam um ambiente que facilita e torna atrativo o ensino de matemática, portanto, as sequências didáticas são um conjunto de atividades ligadas entre si, planejadas para ensinar um 
conteúdo, etapa por etapa, sendo organizadas de acordo com os objetivos que o professor quer alcançar para a aprendizagem de seus alunos (BARBOSA, 2002).

Portanto, o objetivo deste trabalho é realizar uma revisão bibliográfica com base em estudos que visam promover uma aprendizagem significativa por meio da aplicação da sequência didática na matemática em sala de aula.

\section{APRENDIZAGEM SIGNIFICATIVA}

A Teoria da Aprendizagem Significativa foi elaborada por David Ausubel na década de 1960, nela, é defendido que, para se ter uma aprendizagem com significado, um novo conhecimento deve ser ancorado em um outro conhecimento previamente estabelecido nas estruturas cognitivas do aprendiz (AUSUBEL, 2003).

Segundo Silva (2018) a teoria parte da premissa de que existe na mente do indivíduo uma estrutura na qual a sistematização e a integração do conhecimento se processam, é na estrutura cognitiva que se estabelece a relação entre conceitos.

A teoria da aprendizagem significativa tem como pressuposto principal a relação de conteúdos, que vão se agregando de forma hierarquizada e mais complexa de acordo com a ligação a conhecimentos prévios - os chamados subsunçores -, os quais funcionam como "âncoras", propiciando tanto a aprendizagem, quanto o crescimento cognitivo dos indivíduos (GOMES et al., 2008).

Costuma-se dizer que na aprendizagem significativa se transforma o significado lógico de determinado material em significado psicológico; na medida em que o aprendiz internaliza a informação, transformando-a em um conhecimento idiossincrático. Desse modo se consuma a aprendizagem significativa, de maneira que a nova informação será incorporada na estrutura cognitiva do aprendiz, usando o seu modo peculiar de fazer isso (TAVARES, 2010). 
De acordo com Moreira (2003) é preciso entender que a aprendizagem é significativa quando novos conhecimentos (conceitos, ideias, proposições, modelos, fórmulas) passam a significar algo para o aprendiz, quando ele ou ela é capaz de explicar situações com suas próprias palavras, quando é capaz de resolver problemas novos, enfim, quando compreende.

Em uma aprendizagem significativa não acontece apenas a retenção da estrutura do conhecimento, mas se desenvolve a capacidade de transferir esse conhecimento para a sua possível utilização em um contexto diferente daquele em que ela se concretizou (TAVARES, 2008).

Tavares (2010) afirma que na interação entre o conhecimento novo e o conhecimento antigo ambos serão modificados de uma maneira específica por cada aprendiz, como consequência de uma estrutura cognitiva peculiar a cada pessoa.

De acordo com Pelizzari (2002), a) o aluno precisa estar disposto a aprender: se ele simplesmente quiser memorizar o conteúdo de maneira literal e arbitrária, a aprendizagem será mecânica; b) o conteúdo deve ser lógico e psicologicamente significativo: o significado lógico depende somente da natureza do conteúdo, e o significado psicológico é uma experiência que cada indivíduo tem. Cada aprendiz faz uma filtragem dos conteúdos que têm significado ou não para si próprio.

Segundo Lemos et al. (2011) quando a estrutura cognitiva do indivíduo não possui subsunçores diferenciados e estáveis para ancorar (subsumir) a nova informação, o indivíduo a armazenará de forma literal e não substantiva, ou seja, realizará aprendizagem mecânica.

A aprendizagem mecânica ou memorística conforme Tavares (2010) se realiza a partir da absorção literal e não substantiva do novo material. O esforço necessário para esse tipo de aprendizagem é muito menor, daí ele ser tão utilizado quando os alunos se preparam para exames escolares, segundo o autor apesar de custar menos esforço 
a aprendizagem memorística é volátil, com um grau de retenção baixíssimo na aprendizagem de médio e longo prazo.

Ausubel defende que embora a aprendizagem mecânica é necessária em alguns momentos, as ideias aprendidas dessa forma são mais facilmente esquecidas, ao passo que os conhecimentos aprendidos significativamente constituem-se em uma aprendizagem mais eficaz (RORATTO et al., 2016).

Aprender significativamente é, pois, o grande objetivo. Os padrões dogmáticos de uma educação disciplinadora e bancária são quebrados e a relação professor/aluno se transforma em uma relação mestre/aprendiz, sem a rigidez de papéis pré-fixados. Há, então, flexibilização da participação dos atores, na medida em que o aprendiz é também mestre e vice-versa (GOMES et al., 2008).

\section{SEQUÊNCIA DIDÁTICA}

Segundo Pais (2002) uma sequência didática é formada por um certo número de aulas planejadas e analisadas previamente com a finalidade de observar situações de aprendizagem, envolvendo os conceitos previstos na pesquisa didática.

BARBOSA (2002) afirma que a sequência didática consiste em uma série de atividades que criam um ambiente de modelagem matemática, portanto, segundo o autor as sequências didáticas são um conjunto de atividades ligadas entre si, planejadas para ensinar um conteúdo, etapa por etapa. São organizadas de acordo com os objetivos que o professor quer alcançar para a aprendizagem de seus alunos.

Zabala (1998) conceitua a sequência didática como um conjunto de atividades ordenadas, estruturadas e articuladas para a realização de certos objetivos educacionais que têm um princípio e um fim conhecidos tanto pelo professor como pelos alunos. Para Sedano et al (2009) o uso da sequência didática no ensino pode proporcionar momento para que os alunos trabalhem e discutam temas. 
Dolz e Schneuwly (2004) defendem que as sequências didáticas são instrumentos que podem nortear os professores na condução das aulas e no planejamento das intervenções. A sequência de atividade pode ser concebida com base no que os alunos já sabem e, a cada etapa é preciso aumentar o grau de dificuldade, ampliando os conhecimentos prévios desses estudantes, sendo assim, a atividade deve permitir a transformação gradual de seus conhecimentos.

De acordo com Giordan et al. (2011) a estrutura de construção da sequência didática deve seguir os seguintes passos: a) apresentação da situação, definição e formulação da tarefa; b) produção inicial, estabelece o primeiro contato entre o aluno e o gênero textual proposto; c) módulos de atividade, atividades preparadas pelo professor de observação e análise; d) produção final, destinado à prática de elaboração textual.

\section{SequênCIA DidÁtICA e a PromoçÃo da Aprendizagem SignificATIVA}

O ato de aprender possui como principal característica a apropriação de conhecimento dentro de um contexto a partir da realidade concreta, isto é, parte-se da situação real vivida pelo educando apoiado na presença mediadora e gestora do professor compromissado com seus alunos e com a construção de conhecimentos, procurando responder ao princípio da aprendizagem significativa (CASTELLS, 1999).

Vigotski (2001) afirma que os processos de ensino são fundamentais para aquisição dos conhecimentos, assim considera-se que é importante que os professores elaborem situações de ensino que permitam ao aluno estabelecer conexões entre o conhecimento científico e sua compreensão do cotidiano e, nesse sentido, a sequência didática apresenta-se como uma importante metodologia pedagógica destes processos de ensino.

De acordo com Taxini et al. (2012), é de extrema importância conhecer os saberes que os estudantes já possuem para a elaboração de uma sequência didática, 
uma vez que isto auxilia na realização de atividades e discussões, capazes de favorecer a partilha de sentidos e significados dos conteúdos para que estes se ancorem na estrutura cognitiva dos alunos, de modo a subsidiarem a construção de conhecimentos científicos aceitos socialmente.

As pesquisas em Educação Matemática têm se desenvolvido segundo metodologias diversas, em abordagens quantitativas ou qualitativas. Entre as qualitativas, vários esforços podem ser percebidos na construção de sequências didáticas e materiais didáticos em ambientes específicos, computacionais ou não, visando seja o estudo de sua aplicabilidade como o diagnóstico de concepções, dificuldades, obstáculos, níveis de desenvolvimento do raciocínio envolvido, entre outros.

Estudos já têm sido realizados no Brasil com base nesse modo de organizar o ensino, dessa forma pode-se mencionar os trabalhos de alguns autores (de ARAÚJO e GITIRANA, 2000), (RORATTO et al.;2010), (FANTINELLI 2010), (PELLEGRINI, 2014) e (BABINSKI 2017), entre outros.

Araújo e Gitirana (2000) desenvolveram um trabalho para alunos da 6ạ série, com o objetivo de apresentar e analisar didaticamente uma sequência de ensino para a construção do conceito de simetria rotacional, elaboradas num ambiente computacional com o software Cabri-géomètre.

A sequência didática construída pelos autores teve como objetivo criar condições que permitissem aos alunos perceber: a relação entre o número de partes correspondentes que compõe a figura e o ângulo de rotação; a igualdade de distâncias de pontos correspondentes ao centro de rotação; o ângulo que se forma entre os segmentos, que ligam o centro de rotação a dois pontos correspondentes consecutivos. 
Os autores afirmaram que por meio da aplicação do método da sequência didática os objetivos no qual se propôs o estudo foram alcançados, satisfatoriamente, sendo possível perceber que os alunos participaram com grande interesse e motivação durante todas as sessões da sequência didática, apresentando evidências de que avançaram de maneira significativa na compreensão dos conceitos relativos à noção de simetria rotacional ao longo das sessões, desenvolvendo dessa forma a aprendizagem significativa. No entanto os mesmos, reconhecem que a sequência didática experimentada necessita de alguns ajustes, visando uma possível reelaboração.

Roratto et al. (2010) investigaram a possibilidade de se atingir a aprendizagem significativa de Funções, por meio de um ensino fundamentado em seu desenvolvimento histórico, adotando a História da Matemática, em uma perspectiva evolucionista linear, como estratégia para o alcance da aprendizagem significativa, elaborando-se uma sequência didática sobre o conceito de Função.

No trabalho elaborado por Roratto et al. (2010), a sequência didática foi aplicada em uma turma de oitava série (nono ano) de uma escola pública do município de Paranavaí, Paraná. De acordo com os autores, a escolha dessa série se deu pela necessidade de se aplicar a sequência a alunos que não haviam estudado funções previamente, no intuito de que os resultados de aprendizagem detectados fossem consequência da proposta aplicada.

A intervenção para aplicação da sequência didática foi realizada em dez encontros com uma carga-horária de duas horas/aula, sendo divididas a intervenção em três partes: atividades iniciais; desenvolvimento das atividades; avaliação da qualidade da aprendizagem.

Os autores concluíram que, mediante a análise dos mapas conceituais elaborados pelos aprendizes, a História da Matemática em uma perspectiva 
Evolucionista Linear pode levar a ocorrência de Aprendizagem Significativa. No caso das Funções, os autores acreditam que as expressões matemáticas envolvidas terão sentido para os alunos e não serão algo artificial e desprovido de significado. Constataram que, com a abordagem histórica, é possível atingir uma aprendizagem condizente com a descrita na Teoria da Aprendizagem Significativa.

Fantinelli (2010) desenvolveu um trabalho que abordou o ensino de matemática financeira focalizando o conceito e as aplicações dos juros compostos, Fantinelli aplicou sua prática pedagógica em uma turma multisseriada, composta por alunos dos três anos do Ensino Médio, que participaram do curso de Iniciação Profissional em Eletricidade da Fundação Projeto Pescar da Unidade de Cachoeirinha, no Rio Grande do Sul. A autora aplicou uma sequência didática com a utilização de um vídeo sensibilizador, calculadoras científicas e planilhas eletrônicas

Fantinelli (2010) verificou que os alunos não apresentaram dificuldades de entendimento e de realização dos cálculos de montante, bem como a utilização do software Excel. Também, apresentaram um bom desempenho nas atividades desenvolvidas em duplas ou grupos. Da mesma forma, demonstraram entusiasmo e interesse durante todas as etapas das atividades, o que resultou no correto entendimento do conceito de cálculos envolvendo juros compostos.

A autora reforça que a ideia de que educar com novas tecnologias é um desafio que se deve enfrentar com profundidade, pois o modelo tradicional de educação já não atende mais as necessidades dos alunos e professores.

Com esta prática, a autora afirma que desenvolveu uma melhor compreensão sobre a utilização do vídeo como recurso didático para o ensino de juros compostos, pois percebeu que esta associação facilitou o entendimento dos alunos, uma vez que puderam visualizar na reportagem situações comuns a seu cotidiano, que foram representadas matematicamente. 
No Paraná, Pellegrini (2014) buscando contribuir com o ensino de Matemática, e possibilitar ao aluno uma aprendizagem significativa desenvolveu o projeto: "Uma sequência didática Matemática como suporte pedagógico para trabalhar os conceitos da adição e subtração de fração com alunos do $7^{\circ}$ ano do Ensino Fundamental" na Rede Estadual de Educação do Paraná.

A sequência didática do projeto de Pellegrini (2014) foi organizada em 5 (cinco) seções: - Adição e subtração com frações - denominadores iguais - Equivalência de Frações com tiras de papel - Quebra-cabeça - Operando com denominadores diferentes - Comparando as partes com inteiro e operando com o Tangran - adição e subtração de frações com denominadores diferentes associando as partes com o inteiro.

Após a implementação da sequência didática, a autora constatou que a forma de abordagem e as relações propostas nas atividades favoreceram o aprendizado dos alunos do 70 ano do Ensino Fundamental de forma significativa, pois os mesmos demonstraram empenho, envolvimento e interesse em desenvolver as atividades. Segundo a autora o aluno precisa ter acesso aos conhecimentos compreendendo a sua essência, daí a necessidade de se buscar novas metodologias de ensino que proporcione um aprendizado significativo.

Já Babinski (2017) elaborou e aplicou uma sequência didática em sala de aula, para alunos do 9o ano do Ensino Fundamental, que frequentavam a Associação Vida no município de Sorriso/MT. De acordo com o autor buscou-se por meio da sequência didática envolver os alunos nos estudos de Geometria, a fim de problematizar, refletir conceitos e minimizar problemas de aprendizagem.

O estudo de Babinski (2017) iniciou a sequência didática com razão e proporção de figuras geométricas, sendo na sequência trabalhado semelhança de triângulos para 
posteriormente realizar atividades com medidas inacessíveis, o autor afirma que se respeitou os conhecimentos prévio dos estudantes.

Conforme o autor, o objetivo do estudo foi alcançado com a aplicação da sequência didática, uma que vez que os estudantes conseguiram realizar a medida inacessível no encerramento do trabalho, e também desenvolveram de maneira satisfatória e reflexiva os conceitos, bem como compreenderam, questionaram e discutiram os conteúdos trabalhados em cada etapa do estudo. No entanto, o mesmo ressalta a importância de se buscar novas e diferentes estratégias para melhorar as práticas em sala de aula por parte dos professores, neste caso de matemática.

\section{CONSIDERAÇÕES FINAIS}

A aprendizagem significativa leva em consideração o conhecimento prévio do aluno, o qual é motivado por uma situação que faça sentido, proposta pelo professor, o aluno amplia, avalia, atualiza e reconfigura a informação anterior, transformando-a em nova.

Nesse sentido o aluno deve ser visto pelo professor como alguém dotado de saber, o qual não deve ser ignorado, mas ser levado em consideração para que seja feita uma relação desse saber que possui com os conteúdos a serem ensinados na escola, de modo que ocorra efetivamente a aprendizagem significativa, ou seja, que sejam aprendizados que façam sentido para a existência do aluno e por isso mesmo sejam efetivamente aprendidos.

A perspectiva da teoria da aprendizagem significativa proposta por David Ausubel, leva em consideração o funcionamento orgânico do cérebro, o qual realiza as ligações sinápticas, os impulsos elétricos, conforme os estímulos recebidos, sendo essas ligações, possibilidades de percepção, compatíveis com o histórico de vida, de experiências do indivíduo. 
Assim, surgem como recursos que auxiliam na aprendizagem do aluno, perguntas feitas a esse pelo professor, de modo que o aluno desenvolva a resposta conforme o conhecimento que já possui; bem como que seja estabelecido um diálogo que incite a reflexão do aluno, e que leve o professor a sondar o seu entendimento a respeito do tema proposto.

Portanto, por meio da realização deste trabalho, pode-se verificar que em suma a aprendizagem significativa expressa o fato de que tudo o que se realmente aprende é porque se trata de algo necessário para a existência ou sobrevivência do indivíduo, ou seja, se faz necessário que haja uma relação direta entre o conteúdo ensinado, com a experiência e histórico de vida do aluno, de modo que os novos conhecimentos interajam com os já existentes, vindo a agregar ainda mais o saber do aluno, e a aplicação de uma sequência didática bem elaborada depende da associação do conceito desta teoria para obtenção de um êxito satisfatório na aprendizagem do aluno. 


\section{REFERÊNCIAS}

Ausubel, David. Aquisição e retenção de conhecimentos: Uma perspectiva cognitiva. Lisboa: Editora Plátano, 2003.

BABINSKI, Adriano Luís. Sequência Didática (SD): experiência da matemática. 89 fls. 2017. (Dissertação Mestrado). Universidade do Estado de Mato Grosso, 2017.

BARBOSA, Ruy Madsen. Descobrindo a geometria fractal: para a sala de aula. Belo Horizonte: Autêntica, 2002

BEHAR, Patrícia Alejandra; PASSERINO, Liliana Maria; BERNARDI, Maira. Modelos Pedagógicos para Educação a Distância: pressupostos teóricos para a construção de objetos de aprendizagem. RENOTE: revista novas tecnologias na educação [recurso eletrônico]. Porto Alegre, RS, 2007.

DE ARAÚJO, Abraão Juvêncio; GITIRANA, Verônica. Construção do conceito de simetria rotacional através de um ambiente no cabri-géomètre: análise de uma seqüência didática. Reunião Anual, 2000.

DOLZ, J. e SCHNEUWLY, B. Gêneros e progressão em expressão oral e escrita. Elementos para reflexões sobre uma experiência suíça (francófona). In Gêneros Orais e escritos na escola. Campinas (SP): Mercado de Letras. 2004.

FANTINELLI, Ana Lúcia. Engenharia Didática: articulando um referencial metodológico para o ensino de Matemática Financeira. 2010.

GIORDAN, Marcelo; GUIMARÃES, Yara AF; MASSI, Luciana. Uma análise das abordagens investigativas de trabalhos sobre sequências didáticas: tendências no ensino de ciências. Anais do VIII Encontro Nacional de Pesquisa em Educação em Ciências, v. 5, 2011.

GOMES, Andréia Patrícia et al. A educação médica entre mapas e âncoras: a aprendizagem significativa de David Ausubel, em busca da arca perdida. Rev bras educ méd, v. 32, n. 1, p. 105-11, 2008.

MOREIRA, Marco Antônio. Linguagem e aprendizagem significativa. In: Conferência de encerramento do IV Encontro Internacional sobre Aprendizagem Significativa, Maragogi, AL, Brasil. 2003.

PAIS, LUIZ Carlos. Didática da Matemática: uma análise da influência francesa. Belo Horizonte: Autêntica, 2002.

Pelizzari A, Kriegl ML, Baron MP, Finck NTL, Dorocinski SI. Teoria da aprendizagem significativa segundo Ausubel. Revista PEC. 2002;2(1):37-42. 
PELLLEGRINI. S A. P. Uma sequência didática como suporte pedagógico para se trabalhar os conceitos da adição e subtração: uma Intervenção com os alunos do $7^{\circ}$ ano do ensino fundamental. CADERNOS, P. D. E, 2014.

RORATTO, Cauê; NOGUEIRA, Clélia Maria Ignatius; KATO, Lílian Akemi. Ensino de matemática, história da matemática e aprendizagem significativa: uma combinação possível. Investigações em Ensino de Ciências, v. 16, n. 1, p. 117-142, 2016.

RORATTO, Cauê; NOGUEIRA, Clélia Maria Ignatius; KATO, Lílian Akemi. Indícios de aprendizagem significativa mediante o uso de uma sequência didática fundamentada na história das funções. V Colóquio de História e Tecnologia no ensino da Matemática, Recife, Brasil, 2010.

SILVA, Isac. Construção de uma sequência didática para a aprendizagem significativa de tratamento de água. São Paulo: Universidade Cruzeiro do Sul, 2018. 23 f. : il. Produto educacional (Mestrado em Ensino de Ciências e Matemática).

TAVARES, Romero. Aprendizagem significativa e o ensino de ciências. Ciências \& cognição, v. 13, n. 1, 2008.

TAVARES, Romero. Aprendizagem significativa, codificação dual e objetos de aprendizagem. Brazilian Journal of Computers in Education, v. 18, n. 02, p. 04, 2010.

TAXINI, Camila Linhares et al. Proposta de uma sequência didática para o ensino do tema" Estações do Ano" no Ensino Fundamental. Ensaio Pesquisa em Educação em Ciências, v. 14, n. 1, p. 81-97, 2012.

VIGOTSKI, Lev S. A construção do pensamento e da linguagem. São Paulo: Martins Fontes, 2001.

ZABALA, Antoni. A Prática educativa: como ensinar. Tradução Ernani F. da F. Rosa. Porto Alegre: Artmed, 1998. 